\title{
Venous leg ulcers: a prognostic index to predict time to healing
}

\author{
A I Skene, J M Smith, C J Doré, A Charlett, J D Lewis
}

\begin{abstract}
Objective-To evaluate the prognostic factors in uncomplicated venous leg ulcer healing.

Design-Randomised parallel group controlled trial with subjects stratified by initial ulcer diameter and four months' maximum duration of follow up.

Setting-Assessment at Northwick Park Hospital vascular unit with community based treatment.

Patients -200 patients with clinical and objective evidence of uncomplicated venous leg ulceration and an initial ulcer diameter $>2 \mathrm{~cm}$.

Main outcome measure-Time to complete healing of the ulcer.

Results-In the presence of graduated compression healing occurred more rapidly in patients with a smaller initial ulcer area (relative risk of healing 1.92 associated with halving of ulcer area $(95 \%$ confidence interval 1.58 to $2 \cdot 33$ )), shorter duration of ulceration (relative risk 1.35 associated with halving duration $(1 \cdot 17$ to $1 \cdot 56)$ ), younger age (relative risk 1.34 associated with 10 year decrease $(1 \cdot 12$ to $1 \cdot 59))$, and no deep vein involvement (relative risk 1.8 (1.19 to $2 \cdot 78)$ ).
\end{abstract}

Conclusion-These prognostic factors used in a simple scoring system predict time to healing.

\section{Introduction}

The treatment of patients with leg ulcers is predominantly community based and is both time consuming and costly. Nearly $1 \%$ of the population is subject to ulceration,' with an increased prevalence among elderly people. The changing demographics of the population and the tendency for the condition to recur produce a continuing strain on resources. The cost to the NHS per year for each unhealed ulcer has been estimated at $£ 1067$, the largest element being the cost of district nurse time. ${ }^{2}$

There is at present no consensus on proved pharmacological treatments, many studies suffering from inadequate patient numbers, poor design, and failure to standardise compression. In addition, the effect of any particular dressing or drug treatment has tended to be obscured by the unquantified prognostic factors related to the ulceration itself.

The aim of this analysis was to produce a simple scoring system to predict prognosis. The prognostic index evaluates the probability of complete healing with standard ulcer treatments by careful assessment of the prognostic factors at presentation. Thus it may be possible to clarify therapeutic issues in ulcer management and appropriately orient resources to those patients with a poor prognosis.

\section{Patients and methods}

The analysis was based on data from 200 patients with leg ulceration who intially took part in a prospective randomised parallel group controlled trial. The detailed results of the trial, which compared a new hydrocolloid dressing with a standard tulle and iodine dressing, are reported elsewhere. ${ }^{3}$ The inclusion criteria were leg ulcers of greater than $2 \mathrm{~cm}$ diameter of venous or traumatic origin. Patients were excluded with diabetes, rheumatoid arthritis, arterial disease with resting ankle/brachial systolic pressure (ankle pressure index $<0 \cdot 75$, neurological disease causing trophic impairment, infected ulcers which precluded dressing being left in situ, and known intolerance of iodine. Two hundred of the 529 patients initially assessed fulfilled the selection criteria and consented to the trial, which had local ethical committee approval.

All patients were initially assessed in the hospital outpatient vascular clinic, where extensive entry data were recorded. Arterial circulation was assessed by continuous wave ultrasonography ${ }^{45}$ with an ankle pressure index $<0.9$ taken to indicate an element of arterial disease. ${ }^{\circ}$ Venous circulation was assessed by continuous wave ultrasonography and photoplethysmography to indicate deep vein involvemen (popliteal valve incompetence) or superficial vein involvement (incompetence of long or short saphenous vein). ${ }^{6}$ Ulcer area was calculated by triplicate tracing of the outline of the ulcer on to acetate and recording the mean area by planimetry. Obesity was estimated from the body mass index of weight $/$ height ${ }^{2}\left(\mathrm{~kg} / \mathrm{m}^{2}\right)$. Blood pressure, age, fixation of ankle joint, and the history of ulceration were also all recorded for each patient. Bacteriological growth and ulcer area were assessed on entry and at monthly clinic visits.

Patients were reassessed in the clinic monthly for four months or until the ulcer completely healed. Compression was standardised to either two layers of shaped Tubigrip or a Venosan stocking. This provided reproducible linear graduated compression to improve venous function, as described.$^{78}$

\section{Statistical methods}

The time to ulcer healing was used as the dependent variable in a Cox proportional hazards model fitted by using the biomedical data programs package $2 \mathrm{~L} .{ }^{9}$ All possible subsets model fitting was performed by the method of Kuk. ${ }^{10}$ An additional criterion was that each covariate in the best model must be significant at the $1 \%$ level in the likelihood ratio test. Relative risks were calculated and model assumptions of proportional hazards checked by the methods described by Christensen. ${ }^{11}$ These results were then used to produce a simple scoring system for the prognostic index based on the proportional hazards model.

The prognostic index of a patient at presentation wa defined as: $\hat{\beta}_{1} \cdot z_{1}+\hat{\beta}_{2} \cdot z_{2}+\ldots+\hat{\beta}_{n} \cdot z_{n}$, where $\hat{\beta}_{i}$ is the regression coefficient of the $i^{\text {th }}$ variable in the mode and $z_{i}$ is the value of the $i^{\text {th }}$ variable at presentation The cut points required to categorise each variable were obtained by taking the ratio of the prognostic index contribution and the regression coefficient and back transforming to the natural scale of measurement. The sign of the prognostic index was made positive in order to further simplify this scoring system. 


\section{Results}

The baseline characteristics of the 200 patients recruited are presented in table I. One hundred and forty patients completed the four months of the trial, and 97 patients (49\% of those recruited) had healed ulcers. Patients who were withdrawn $(n=60)$ or failed to heal $(n=43)$ were retained in the analysis as censored observations. Reasons for withdrawal were patient requests (23 cases), acute infections (13), hospital admissions (12), allergic reactions (eight), deaths (two), and patients leaving the area (two).

Cox proportional hazards models were fitted to the data from all patients in order to predict time to healing. All the variables in table I were considered as possible covariates. The regression coefficients for the final model are shown in table II. The regression coefficient for treatment indicated that healing was more rapid when the hydrocolloid dressing was used, but this was not significant $(p=0 \cdot 48)$. The relative risk of healing for patients with no deep vein involvement compared with those with deep vein involvement (popliteal valve incompetence) was $1.8(95 \%$ confidence interval 1.19 to 2.78 ) - that is, an ulcer was 1.8 times as likely to heal during the four months of follow up if the patient had no deep vein involvement. The relative risk of healing associated with a halving in initial ulcer area

TABLE I-Baseline characteristics of patients. Values are means (SD) unless stated otherwise

\begin{tabular}{llc}
\hline & \multicolumn{2}{c}{ Initial maximum ulcer diameter } \\
\cline { 2 - 3 } & \multicolumn{1}{c}{$\begin{array}{c}2-4 \mathrm{~cm} \\
(\mathrm{n}=126)\end{array}$} & $\begin{array}{c}>4 \mathrm{~cm} \\
(\mathrm{n}=74)\end{array}$ \\
\hline Age (years) & $73(13)$ & $75(10)$ \\
Diastolic blood pressure (mm Hg) & $82(15)$ & $84(14)$ \\
Body mass index (kg/m) & $27 \cdot 5(7 \cdot 0)$ & $28 \cdot 8(7 \cdot 1)$ \\
Superficial vein involvement on & & \\
$\quad$ photoplethysmography (No (\%)) & $42(35)$ & $24(33)$ \\
Deep vein involvement on & & \\
$\quad$ photoplethysmography (No (\%)) & $62(51)$ & $36(50)$ \\
Ankle pressure index <0.9 (No (\%)) & $8(6)$ & $9(12)$ \\
Venosan stocking worn (No (\%)) & $93(74)$ & $49(66)$ \\
Fixed ankle joint (No (\%)) & $24(19)$ & $17(23)$ \\
Previous venous leg ulcers (No (\%)) & $77(61)$ & $45(61)$ \\
Initial ulcer area (cm:) (median & & \\
$\quad$ (interquartile range)) & $2 \cdot 7(1 \cdot 8-4 \cdot 3)$ & $14 \cdot 2(9 \cdot 1-30 \cdot 0)$ \\
Duration of ulceration (months) (median & & \\
$\quad$ (interquartile range)) & $4 \cdot 0(2 \cdot 0-9 \cdot 0)$ & $16 \cdot 0(4 \cdot 8-53 \cdot 3)$ \\
Bacteria present at initial assessment & & \\
$\quad$ No (\%)): & $3(2)$ & $13(18)$ \\
$\quad$ Pseudomonas & $60(50)$ & $37(51)$ \\
$\quad$ Staphylococcus aureus & $5(4)$ & $7(10)$ \\
$\quad$ Haemolytic streptococci & $52(43)$ & $38(53)$ \\
Other organisms & $23(19)$ & $4(6)$ \\
$\quad$ None found & & \\
\hline
\end{tabular}

Percentages calculated using all recorded data.

TABLE II-Cox proportional hazards model predicting days to ulcer healing

\begin{tabular}{|c|c|c|c|}
\hline Variable & Coefficient & SE & $\mathrm{p}$ Value \\
\hline $\begin{array}{l}\text { Ulcer area }\left(\mathrm{cm}^{3}\right)\left(\log _{10}(\mathrm{x})\right) \\
\text { Duration of ulceration (months) }\end{array}$ & $-2 \cdot 1709$ & $0 \cdot 3273$ & $<0.001$ \\
\hline$\left(\log _{10}(x+1)\right)$ & -0.9991 & $0 \cdot 2466$ & $<0.001$ \\
\hline Age (years) & -0.0289 & 0.0089 & 0.002 \\
\hline $\begin{array}{l}\text { Deep vein involvement on } \\
\text { photoplethysmography }(0=\text { no, } 1=\text { yes })\end{array}$ & $-0 \cdot 5886$ & 0.2143 & 0.006 \\
\hline
\end{tabular}

Estimated probability of ulcer healing in 40,80, and 120 days by prognostic index, based on proportional hazards model regression coefficients in table II
TABLE UI-Scoring system to estimate prognostic index for venous ulcer healing

\begin{tabular}{|c|c|c|}
\hline Covariate & Category/classification & $\begin{array}{l}\text { Prognostic } \\
\text { index } \\
\text { score }\end{array}$ \\
\hline $\begin{array}{l}\text { Ulcer area }\left(\mathrm{cm}^{2}\right) \text { (estimated mean } \\
\left.\text { diameter }{ }^{\star}\right)\end{array}$ & $\left\{\begin{array}{l}<1 \cdot 7(<1 \cdot 5) \\
1 \cdot 7(1 \cdot 5) \text { to } 4 \cdot 89(2 \cdot 4) \\
4 \cdot 9(2 \cdot 5) \text { to } 14 \cdot 19(4 \cdot 1) \\
14 \cdot 2(4 \cdot 2) \text { to } 40 \cdot 89(7 \cdot 1) \\
40 \cdot 9(7 \cdot 2) \text { to } 118 \cdot 3(12 \cdot 2) \\
>118 \cdot 3(>12 \cdot 2)\end{array}\right.$ & $\begin{array}{l}0 \\
1 \\
2 \\
3 \\
4 \\
5\end{array}$ \\
\hline Duration of ulceration (months) & $\left\{\begin{array}{c}<2 \\
2-31 \\
>31\end{array}\right.$ & $\begin{array}{l}0 \\
1 \\
2\end{array}$ \\
\hline Age (years) & $\left\{\begin{array}{l}<52 \\
52-86 \\
>86\end{array}\right.$ & $\begin{array}{l}1 \\
2 \\
3\end{array}$ \\
\hline $\begin{array}{l}\text { Deep vein involvement on } \\
\text { photoplethysmography }\end{array}$ & $\left\{\begin{array}{l}\text { No } \\
\text { Yes }\end{array}\right.$ & $\begin{array}{l}0 \\
0.5\end{array}$ \\
\hline
\end{tabular}

* Mean diameter calculated with ulcer assumed to be circular.

TABLE IV-Proportion of ulcers healed within four months by prognostic index

\begin{tabular}{lccccc}
\hline $\begin{array}{l}\text { Prognostic } \\
\text { index }\end{array}$ & Healed & $\begin{array}{c}\text { Not } \\
\text { healed }\end{array}$ & Total & $\begin{array}{c}\% \\
\text { Healed }\end{array}$ & $\begin{array}{c}\text { Median time to healing } \\
\text { (days) }\end{array}$ \\
\hline $1-4$ & 49 & 22 & 71 & 69 & 40 \\
$4 \cdot 5-5 \cdot 5$ & 39 & 33 & 72 & 54 & 70 \\
$\geqslant 6$ & 4 & 45 & 49 & 8 & $118^{\star}$
\end{tabular}

* Median time of follow up (median time to healing 92.5 days in those four ulcers that healed).

was $1.92(1.58$ to 2.33$)$. The relative risk of healing associated with halving the duration of ulceration was $1.35(1.17$ to 1.56$)$. The relative risk of healing associated with a 10 year decrease in age was $1.34(1.12$ to 1.59). The type of dressing and the ulcer diameter initially used to stratify the patients in this study were not independently significant factors.

The regression coefficients in table II were used to formulate a simple scoring system, shown in table III, in order to obtain an estimate of the prognostic index for an individual patient. For example, the prognostic index for a 63 year old patient with a nine month history of an ulcer with an area of $4 \mathrm{~cm}^{2}$ with no deep vein involvement was calculated as: $2+1+1+0=4$. The higher the value of the prognostic index the longer the ulcer will take to heal. For a given prognostic index the probability of the ulcer healing in 40,80 , or 120 days can be determined from the figure. In the example above with a prognostic index of 4 there is a $17 \%$ chance of the ulcer healing in 40 days, $47 \%$ in 80 days, and $77 \%$ in 120 days. The observed proportion of ulcers healed after four months and the median time to healing in high, medium, and low risk groups are given in table IV.

\section{Discussion}

Several groups have investigated the prognostic factors which affect venous ulcer healing. Stewart and Leaper found a relation with ulcer area and duration. ${ }^{12}$ Kikta et al found a relation with ulcer area, ${ }^{13}$ while Colgan $e t ~ a l^{14}$ found no significant relations. All these studies were based on fewer than 100 patients and so lacked power. These prognostic factors are supported by our study, although none of the smaller studies found age and deep vein involvement to be associated with venous ulcer healing. Age was determined to be a prognostic factor independent of arterial disease or hypertension. This fact may contribute to the increased prevalence of venous ulceration observed in elderly 8 people. ${ }^{\circ}$ The predicted demographic shift in the elderly population is likely to increase the need for care $\overline{0}$ of this condition.

Measurement of ulcer area is preferable to mean ulcer diameter because it is a stronger predictor of ulcer 
healing. The irregularity of ulcer shape means there is no direct relation between ulcer diameter and area. Nevertheless, either method can be used to calculate the prognostic index and both are included as alternatives for scoring in table III.

The presence of bacterial contamination seems to be of little relevance to venous ulcer healing. ${ }^{15} \mathrm{We}$ found no association between bacteria present at the start of the trial and ulcer healing. However, we also observed that the bacteria present change from month to month. This agrees with Ormiston et al, who found no consistent trend towards eradication of particular pathogens irrespective of the treatment or response of the ulcers. ${ }^{16}$

It seems logical to recommend that the four identified factors should be taken into consideration in the future when comparing methods of treatment. The prognostic index score can be used to stratify patients into high, medium, and low risk groups. This would make the treatment groups more comparable. Alternatively, all four prognostic factors could be incorporated into the model when assessing treatment effects. The prognostic index has been derived and verified on the same data. A repeat study may not obtain as clear a graduation of patients as shown in table IV.

The prognostic index is also valuable for individual patients. If the probability of the ulcer healing is known, then this information can help to formulate appropriate management decisions ${ }^{17}$ and orient resources to those individuals with a poor prognosis.

We thank the study's nurse coordinators J V Cornwall and W Jones, Clinimed Ltd for the financial support of W Jones, the community nurses who helped with the study, and $\mathrm{O}$ Waldron for typing the manuscript.

1 Callam MJ. Prevalence of chronic leg ulceration and severe chronic venous disease in Western countries. Phlebology 1992;7(suppl 1):6-12.

2 Bosanquet N. Costs of venous ulcers: from.maintenance therapy to investment programmes. Phlebology 1992; 7(suppl 1):44-6.

3 Smith JM, Doré CJ, Charlett A, Lewis JD. A randomized trial of Biofilm dressing for venous leg ulcers. Phlebology 1992;7:107-13

4 Yao ST, Hobbs JT, Irvine WT. Ankle systolic pressure measurements in arterial disease affecting the lower extremities. Br I Surg 1969;56:676-9.

5 Cornwall JV. Diagnosis of leg ulcers. Fournal of District Nursing 1985;Sept $4-6,11$

6 Cornwall JV, Dore CJ, Lewis JD. Leg ulcers: epidemiology and aetiology Brf Surg 1986;73:693-6.

7 Jones NAG, Webb PJ, Rees RI, Kakkar VV. A physiological study of elastic compression stockings in venous disorders of the leg. $\mathrm{Br} \mathcal{J}$ Sur 1980;67:569-72.

8 Cornwall JV, Dore CJ, Lewis JD Graduated compression and its relation to venous refilling time. $B M 71987 ; 295: 1087-90$.

9 Dixon WJ, Brown MB, Engelman L Hill MA, Jennrich RI. BMDP starissical software manual. Vols 1, 2. Berkeley, California: University of California Press, 1988.

10 Kuk AYC. All subsets regression in a proportional hazards model. Biometrik 1984;71:587-92.

11 Christensen E. Multivariate survival analysis using Cox's regression model. Hepatology 1987;7:1346-58.

12 Stewart AJ, Leaper DJ. Treatment of chronic leg ulcers in the community: comparative trial of Scherisorb and Iodosorb. Phlebology 1987;2:115-21.

13 Kikta MJ, Schuler JJ, Meyer JP, Durham TR, Eldrup-Jorgensen T, Schwarcz $\mathrm{TH}$, et al. A prospective, randomized trial of Unna's boots versus hydroactive dressing in the treatment of venous stasis ulcers. I Vasc Surg 1988;7:478-83.

14 Colgan MP, Dormandy JA, Jones PW, Schraibman IG, Shanik DG Young $\cdot$ RAL. Oxpentifylline treatment of venous ulcers of the leg. $B M$ 1990;300:972-4.

15 Eriksson G. Bacterial growth in venous leg ulcers-its clinical significance in the healing process. In: Ryan TJ, ed. An environment for healing: the role of occlusion. London: Royal Society of Medicine, 1984:45-9.

16 Ormiston MC, Seymour MTJ, Venn GE, Cohen RI, Fox JA. Controlled tria of Iodosorb in chronic venous ulcers. BMg 1985;291:308-10.

17 DeFriend DJ, Edwards AT, McCollum C. Treatment of venous ulcerationwhen is surgical management indicated? Phlebology 1992;7(suppl 1):33-7.

(Accepted 8 September 1992)

\section{Oral cancer in Scotland: changing incidence and mortality}

\section{Gary J Macfarlane, Peter Boyle, Crispian Scully}

\section{Abstract}

Objectives-To determine the incidence of oral cancer in Scotland between 1960 and 1989 and oral cancer mortality from 1911 to 1989.

Setting-Data were obtained on oral cancer incidence from the information and statistics division of the Common Services Agency of the Scottish Health Service and mortality data from the office of the registrar general for Scotland.

Results-Mortality from intraoral cancers in Scotland substantially declined throughout this century until the mid-1970s. This trend, however, was then reversed, and fourfold increases in incidence were observed in younger age groups after 1960. Death rates in these younger age groups increased to levels previously recorded in the $1940 \mathrm{~s}$. These increases seemed to be cohort based and may therefore continue into the future.

Conclusions-Reasons for increasing rates among younger age groups are speculative and rely on combining knowledge about risk factors and available ecological data. Though increases in incidence at younger ages do not result in a large change in the number of cases diagnosed, possible similar increases continuing into older ages, when oral cancer is more common, will correspond to a much larger increase in the actual number of cases. Given that such a large attributable risk is associated with tobacco and alcohol, however, these increases may be preventable.

\section{Introduction}

There are wide geographical differences in the reported incidence rates of intraoral cancer. Tongue cancer in males is most common in India $(9.4$ per 100000 in Bombay), Brazil (7.4 per 100000 in São Paulo), and France (7.9 per 100000 in Doubs), and in females-although rates are much lower-the rates in Bombay (3.4 per 100000) and among Indians in Singapore $(3.3$ per 100000$)$ are considerably higher than those reported from cancer registries in othe countries. Those registries reporting the highest rates of tongue cancer also report high rates of mouth cancer. Low rates for both sites and in both sexes are reported from China, Japan, and northern European countries. At present Scotland has a relatively low incidence of mouth cancer (males 2.0 per 100000 females 0.8 per 100000 ) and tongue cancer (males 1.0 per 100000 ; females 0.6 per 100000 ) in internationa terms. $^{12}$

In the 1960s and 1970s there were several reports of a decrease in the incidence of mouth cancer in the United Kingdom ${ }^{3.5}$ and elsewhere, ${ }^{67}$ although these were based on data over relatively short periods. More recently an increasing incidence and mortality from tongue or mouth cancer, or both, has been noted in some countries, ${ }^{289}$ including Scotland, ${ }^{10}$ this change being particularly evident in young males.

The purpose of this report is to examine time trends in both the mortality from and incidence of intraora cancer in Scotland during this century.

\section{Material and methods}

Mortality data for Scotland are available aggregated by five year periods from 1911 to $1989 .{ }^{112}$ From 1951 data are grouped in five year age classes (0-4 years, $5-9$ years, up to $80-84$ years, and 85 years or over). Before this, however, the data were aggregated in age groups 